\title{
A three-dimensional virtual library model of the ancient Library of Alexandria*
}

\section{István Boda, Erzsébet Tóth, Miklós Bényei, István Csont}

\author{
University of Debrecen, Faculty of Informatics \\ boda.istvan@inf.unideb.hu \\ toth.erzsebet@inf.unideb.hu \\ benyei@unideb.hu \\ ist.csont@gmail.com
}

\begin{abstract}
In our presentation we would like to introduce a virtual library model based on the 3D capabilities of the Virtual Collaboration Arena (VirCA) system developed at the Computer and Automation Research Institute of the Hungarian Academy of Sciences. The model has been developed in order to reap the benefits - the extraordinary navigation and accessibility features, "holistic" characteristics, strong affective power etc. - of the 3D virtual environment presenting selected ancient works (as well as biographies) of some illustrious authors in the light of the modern information technology. In the model the library content is presented in a virtual room where a maximum of 18 cabinets are arranged in two parallel rows. The cabinets contain the relevant information to be presented, so their position and arrangement together with other distinctive features - are crucial to finding the appropriate content in the virtual space. The arrangement of cabinets is based on the classification system of the ancient Library of Alexandria developed by Callimachus in the 3rd century BC. Based on that, we attached certain categories (epic poets, elegists, lyrical poets etc.) to the English translation of the selected ancient Greek texts. In addition, two parallel sequences of some characteristic images are displayed as image corridors next to each cabinet which greatly facilitate finding the relevant information in the virtual room at a single glance. On the basis of those features (cabinets, categories, image corridors etc.) we can group the related information together and compose various "spatial composites" in order to form a well-searchable spatial hypertext system. We have created a database of the selected library materials and developed a PHP-based interface to provide and demonstrate interactive search capabilities. The search results can be obtained in a form of an XML
\end{abstract}

${ }^{*}$ The publication was supported by the TAMOP-4.2.2.C-11/1/KONV-2012-0001 project. The project has been supported by the European Union, co-financed by the European Social Fund. 
file which describes the corresponding virtual room in the VirCA system. In addition, we have created a hypertext (or two-dimensional) representation of the model which simulates the arrangement and atmosphere of the virtual $3 \mathrm{D}$ environment and enables us to compare the 2D and 3D representations of the library model. There are many possible applications and improvements of our three dimensional virtual library model (e.g. in language learning, creating hypertext representation of poetic texts, implementing the model in automated library systems etc.).

Keywords: the ancient Library of Alexandria, three dimensional virtual library model, VirCA system, spatial hypertext, 3D representation of the library content

MSC: 68U05; 68U35; 68P20; 91E10

\section{Why was the Library of Alexandria chosen?}

The Library of Alexandria is the most significant and renowned library of classical (Greek-Roman) antiquity, but its written documents were destroyed or lost - this fact is known only from the contemporary writers' works. It has been representing a symbolic force till nowadays embodying a library ideal especially for modern public libraries and its fame was present in the later ages too. To give an appropriate answer to the above mentioned question we think that it was an important aspect for us that all the Greek written texts gathered in this library were authoritative values for human culture and erudition. In addition, we considered that the analysis of the poetical Greek works had been still an open issue in our days. Therefore we decided to deal with the field of ancient Greek poetry and drama once available in the Great Library of Alexandria. In our research we intended to present these ancient masterpieces in new formats and environment. Thus it was essential for us to attach verbal and multimedia metadata to the English translation of the selected ancient Greek works in the three-dimensional virtual space.

The Musaeum or Mouseion ("Seat of the Muses") at Alexandria was a research institution including several establishments for scientists such as a botanical garden, an observatory, a library etc. It was founded by Ptolemy I Soter and by his son, Ptolemy II Philadelphus at the turn of 4 th and 3rd centuries BC. Its operation resembled much more a university. At that time Egypt was one of the successor states which belonged to the extended empire of Alexander the Great. We have to mention Ptolemy III (Euergetes) who established a subsidiary "daughter library" in the Temple of Serapis about 235 BC. Later it had an important role in the history of the library.

The Library of Alexandria was one of the most important components of the Mouseion funded by the royal treasury. The Ptolemaic dynasty intended to collect all the Greek works in the library, so they wanted to achieve completeness in written Greek literature. Soon the collection has brought together several thousands of papyrus rolls in its holdings. The main objective of the library's editorial program was to establish the Alexandrian canon of Greek poets. The museum and the 
library existed for many centuries, but they were destroyed in the civil war that took place under the Roman emperor Aurelian in the late 3rd century AD; the daughter library was damaged badly by the Christians in AD 391. In 2002 the Egyptian government inaugurated a new library, the Bibliotheca Alexandrina, which was built exactly on the site of the ancient institution [1], [4].

\section{The overview of the classification scheme}

Callimachus organized the operation of the library between 260 and 240 BC. Under his leadership the library catalogue was built, resulted in the so called Pinakes ('tablets'). Its name is originated from certain parts of the catalogue on papyrus leaves which were stuck (possibly written) on wooden tablets. Those tablets were put above chests (or shelves) to support a search for papyrus rolls and to make their reshelf more effective. The title of the catalogue was the following: Tables of Those Who Have Distinguished Themselves in Every Form of Culture and of What They Wrote. In Greek the ,literature” word is used in a broader sense which refers to education or erudition, so Callimachus, being adjusted to the Egyptian ruler's objective, wanted to provide a complete coverage of the Hellenistic culture in the index list of rolls. Applying the author's approach he added a short biography to each author's name and he described the originality and the content of each work. Since the title was seldom clear (if it existed at all), therefore he decided to add the first line of the work to his catalogue and to register how many lines the specific work contained.

The catalogue included 120 books (rolls), and it had recorded approximately 200 000 papyrus rolls. Since the Great Library of the Mouseion was practically complete as regards Greek literary texts, the catalogue is considered to be a bibliography of contemporary Greek literature too. Furthermore, we regard it also as the ancestor of bibliography and science history because of its biographical notes [2].

The structure reflecting the contemporary scientists' and literary men's intellectual system was split into two levels:

- At the higher level there was a categorization of the writers that provided a 'skeleton' of the division.

- At the other level each category was arranged in alphabetical order by the author's name.

Callimachus divided the library materials into two main parts: poets and prosaists. In these categories he created six sub-groups separately.

- poets: epic poets, comic playwrights, satirical poets, lyrical poets, elegists, tragedians;

- prosaists: physicians, natural scientists, historians, speakers, philosophers, miscellanies (here cookery books also emerged with a „dining writers" subtitle) [3]. 


\section{Integration of contents into the library model}

First we intended to implement Callimachus' hierarchical structure in our virtual library model. We selected three famous Greek ancient authors who would represent each sub-group within the "poets" main category. We followed the same author's approach as Callimachus used in his catalogue by combining the author's image or his/her bust with the author' name, and added a short biography to him/her. So it meant that we applied the same content layout that the Pinakes had in ancient times.

The process of integrating contents into this library model is composed of the following steps:

1. We sought for images closely connected to the authors' life and poetical works. These images covered a wide spectrum of artistic works: graphics, marble reliefs, statues, paintings and maps.

2. Then we gathered and edited a brief biography of the selected ancient authors. Pointing to their significance in Greek literature, we presented a short overview about their life and referred to their most important masterpieces. For this task we could use and check various entries in Encyclopedia Britannica and Wikipedia online sources ${ }^{1}$.

3. Concerning copyright restrictions we had to find proper English translation of Greek poetical works on the web. The corresponding electronic version of literary works was available for us in well-known digitization projects such as Project Gutenberg, Google Books Library Project, Perseus Digital Library Project (Tufts University), California Digital Library (University of California). Then the collected English translations were edited in one page $(\mathrm{A} / 4)$ length and in the suitable format.

4. All library content is needed to be loaded into the VIRCA system in a determined logical order and means according to the special features of the software.

\section{Introduction of the $3 \mathrm{D}$ environment}

The current implementation of our three-dimensional virtual library model [5] is based on the presentation and navigation features of the tree-dimensional virtual environment of the Virtual Collaboration Arena (VirCA) system which has been developed by the Cognitive Informatics Research Group of the Computer and Automation Research Institute of the Hungarian Academy of Sciences [6, 7]. The three-dimensional presentation of the selected library content represented as a set

\footnotetext{
${ }^{1}$ http://www.britannica.com/EBchecked/topic/14417/Library-of-Alexandria (et passim); http://en.wikipedia.org/wiki/Library_of_Alexandria (et passim) (2014-04-14)
} 
of $3 \mathrm{D}$ objects placed in the virtual 3D environment has some real benefits compared to the "traditional" lists of records as most of the present-day library systems display the searched and retrieved data from their databases. On the one hand, the users can get a general or "holistic" overview of the presented content including, most of all, the direct and/or suggested relationships of the 3D objects at the first glance; on the other hand, moving and exploring hidden treasures in the "virtual reality" of the $3 \mathrm{D}$ environment of the library has strong affective power or "qualia" just like in several computer games; and last, but not least, the three-dimensional environment has inherent accessibility features because the users can freely navigate in it determining the position of their virtual self in a loose way which is just the opposite to the precise positioning required in a verbally represented and selection-based search interface.

The basic unit of our three-dimensional library model is a virtual 'room' provided by the VirCA system. It can consist of almost any kind and number of 3D objects in different positions, colours, sizes etc. by which we can 'furnish' and decorate the virtual room. In this version of our library model we have implemented cabinets, image corridors, navigators and posters in the first place; these objects and their relationships form a spatial hypertext system presenting the selected library content and, at the same time, their careful selection and arrangement might imitate the atmosphere of the precious environment of the ancient Library of Alexandria.

The back wall of the room contains a reconstructed picture of the ancient Library of Alexandria or 'Mouseion' which, represented as coloured 3D text over the picture, stand for the main 'title' of the room (see Fig 1). On the left and right there are some informative posters describing the brief history of the ancient Library of Alexandria, a map of the respective area, information of Callimachus' system of the library etc.

Next to the front wall of the room there are two parallel rows of a maximum of 18 boxes or 'cabinets' which contain the presented library content (see Fig 2). Each cabinet corresponds to a selected poetic work or a short biography of an ancient author which, once a user decides to enter, can be clearly seen and read inside the cabinet illuminated by a lamp from the ceiling of the cabinet. The 'entrance' of the cabinets has been implemented by a virtual curtain or 'veil' displaying either the title of the represented content or the image of the corresponding ancient author. In addition, there is a label on the top of each cabinet which displays an appropriate category assigned to the content of the cabinet (e.g. epic poets, elegists, lyrical poets etc., according to Callimachus' library system). Its function is to help the users find the appropriate content they are looking for. In order that the users can find the relevant information more easily, we have also attached a sequence of a maximum of four images to each cabinet which can display - from both sides of the cabinet - additional information on or about the content of the cabinet in a form of ancient maps, paintings, antic sculptures or objects, fragments of papyri, book covers etc. These sequences of images serve as 'image corridors' showing the way to the corresponding cabinet in the three-dimensional virtual space. 


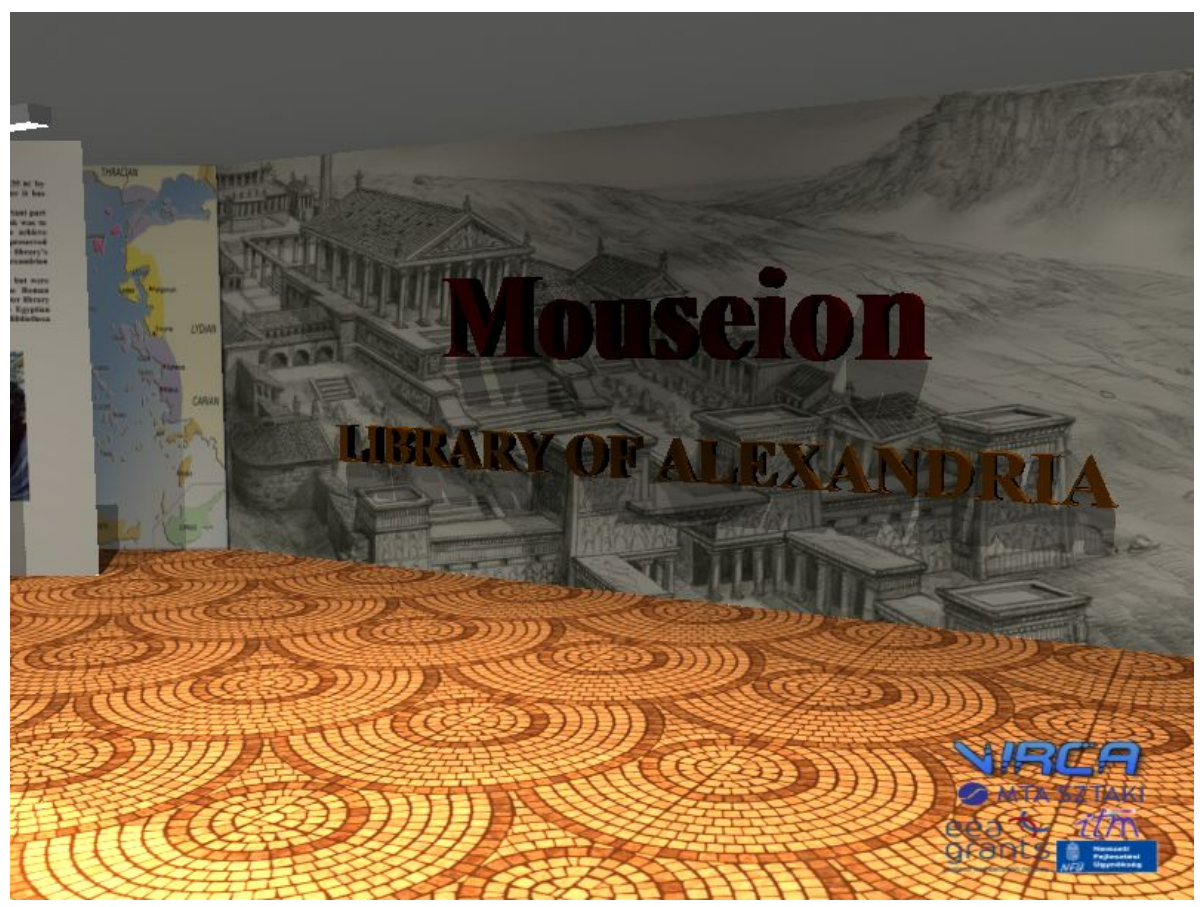

Figure 1: The back wall of the virtual room of the 3D library model

Although there can be other arrangements of the presented library content, in Fig. 2 the cabinets containing the images and short biographies of the ancient authors are in the upper row, and the cabinets containing their works can be found below the corresponding authors' cabinets.

\section{Technical implementation of the library model}

In the VirCA system the virtual room can be described by a well-documented XML file. This flexible and robust approach has considerable benefits; for example, we can create a pre-defined arrangement of the cabinets where most of the parameters are fixed and only a few selected parameters have to be changed depending on the actual content we want to present. Such an arrangement can be easily tested; we have created a Java program which can generate the XML description file according to the selected library content to be arranged and displayed.

In order that the collected data could be searchable we have created a database of the library content using the MySQL open-source relational database management system [8]. A PHP-based interactive interface is provided to create a search query in a HTML form and generate an appropriate SQL statement which can be sent to the MySQL server for processing. The page has been developed using the 


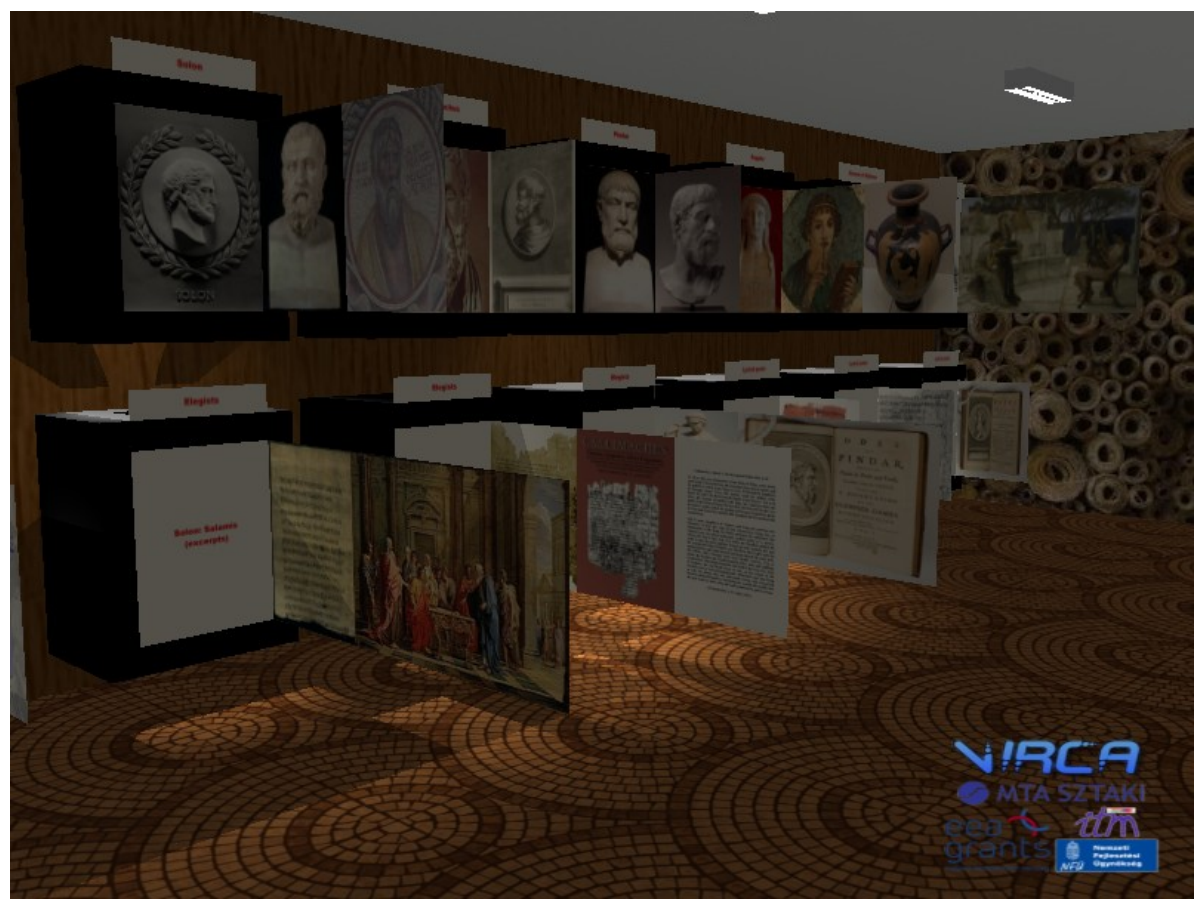

Figure 2: The front wall of the virtual room of the 3D library model and the rows of cabinets

XAMPP open source development package including the Apache web server [9]. The search results can be displayed in several different forms: in addition to the PHP-generated XML room description file which is necessary for the VirCA system, the results can be displayed on a specifically designed web page, which can be considered as a two-dimensional projection of the virtual room, and a hypergraph is generated to illustrate the results and their relationships in a form of a threedimensional map using the freely available HyperGraph Java applet [10]. Finally, we can directly transform the XML data, using an XSL stylesheet, into the form of an HTML/CSS page which is designed to be similar to the virtual room of our 3D library model (see Fig. 3). Here the content of the symbolic 'cabinets' appears when the mouse cursor is moved above the covered image that can be seen behind each cabinet.

\section{Further improvements and applications}

In addition to the practical applications in library systems which seem to be quite tangible and natural, the cognitive aspects of our model can be of considerable importance. One of the most interesting questions is the effectiveness of the holistic 


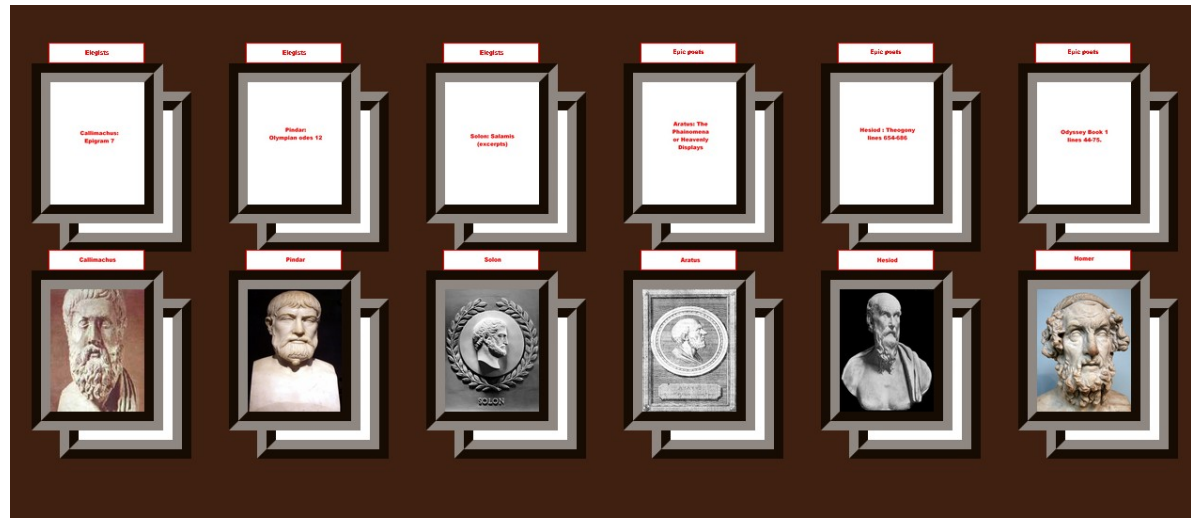

Figure 3: The symbolic presentation of the cabinets in a transformed HTML/CSS page

representation of data; although it is generally and very efficiently used in displaying figures, charts, diagrams etc. but far more rarely when using "traditional" library catalogues and especially in presenting the explicit and implicit (or suggested) relationships among the selected library content. It might also be worth examining the benefits of the associated multimedia content (e.g. the images in the 'image corridors') with respect to the effectiveness for memorizing data. It can be reasonably assumed that the virtual 3D environment might also be used in language learning where the spatial representation of texts could be very illuminating. In addition, a very promising multidisciplinary approach (and challenge) could be to create and compare the $2 \mathrm{D}$ and $3 \mathrm{D}$ hypertext representations of the structure of certain verbal texts, e.g. literary (and especially poetic) texts. Our 3D virtual library model is intended to be used in certain integrated library systems (e.g. to present the search results of a query in an online catalogue). Finally, a very ambitious project can be to develop a truly realistic picture of an existing library collection (an example of which has been introduced in [11]) which can be implemented as another establishment of the virtual room in our three-dimensional library model.

\section{References}

[1] GRÜLL, T., Könyvtárak és könyvkiadás az ókorban. [Libraries and Publishing of Books in the Antiquity.] In: Bevezetés az ókortudományba 1. [Introduction to the Study of Antiquity 1.] : Egyetemi jegyzet. Debrecen: Kossuth Egyetemi K., 1996, $223-231$.

[2] MACLOAD, R., The Library of Alexandria: Center of Learning in the Ancient World. New York: I. B. Tauris \& Co Ltd., 2005. 
[3] EL-ABBADI, M., The Life and Fate of the Ancient Library of Alexandria. (2., illustrated ed.). Unesco/UNDP, 1990.

[4] NOVELLI, G., Alexandriai Könyvtár. Egyiptom, Alexandria [Library of Alexandria. Egypt, Alexandria] In Az építészet csodái: Az ókortól napjainkig [Wonders of Architecture: From Antiquity to Our Days] / [összeáll., szerk. Alessandra Capodiferrp] [compiled, edited by Alessandra Capodiferrp]; [ford. Getto Katalin] [translated by Getto Katalin]. Pécs : Alexandra, 2010, 164--167

[5] VirCA: 3D Virtual Collaboration Arena. http://virca.hu/ (2013-09-19)

[6] GALAMBOS, P. and BARANYI, P., VirCA as Virtual Intelligent Space for RTMiddleware. In AIM 2011. Proceedings of the 2011 IEEE/ASME International Conference on Advanced Intelligent Mechatronics. (Budapest, Hungary, July 3-7 2011,) $140-145$.

[7] BODA, I., BÉNYEI, M., and TÓTH, E., New dimensions of an ancient Library: the Library of Alexandria. In CogInfoCom 2013. Proceedings of the 4th IEEE International Conference on Cognitive Infocommunications. (Budapest, Hungary December $2-5,2013,) 537--542$.

[8] MySQL :: The world's most popular open source database. http://www.mysql.com/ (2014-04-30)

[9] XAMPP Installers and Downloads for Apache Friends. https://www . apachefriends.org/hu/index.html (2014-04-30)

[10] HyperGraph - Free Science \& Engineering software downloads at SourceForge.net. http://sourceforge.net/projects/hypergraph/ (2013-04-16)

[11] GILÁNYI, A. and VIRÁGOS, M., Library Treasures in a Virtual World. In CogInfoCom 2013. Proceedings of the 4th IEEE International Conference on Cognitive Infocommunications. (Budapest, Hungary December 2-5, 2013,) 563--566. 